\title{
Current practices and research updates on diabetes mellitus in canine
}

\author{
Pankaj Kumar ${ }^{1}$, Rashmi Rekha Kumari², Manish Kumar ${ }^{3}$, Sanjiv Kumar ${ }^{4}$ and Asit Chakrabarti ${ }^{1}$
}

1. Division of Livestock and Fisheries Management, ICAR Research Complex for Eastern Region, Patna, Bihar, India;

2. Department of Pharmacology, Bihar Veterinary College, Patna, Bihar, India; 3. Department of Biotechnology, Indian Institute of Technology Guwahati, Assam, India; 4. Department of Pathology, Bihar Veterinary College, Patna, Bihar, India.

Corresponding author: Pankaj Kumar, e-mail: pankajvet@gmail.com,

RRK: rrkvet@gmail.com, MK: manishvet@gmail.com, SK: mrsanvet@rediffmail.com, AC: asit1963@yahoo.com

Received: 31-07-2014, Revised: 05-10-2014, Accepted: 09-10-2014, Published online: 14-11-2014

doi: 10.14202/vetworld.2014.952-959. How to cite this article: Kumar P, Kumari RR, Kumar M, Kumar S, Chakrabarti A (2014) Current practices and research updates on diabetes mellitus in canine, Veterinary World 7(11): 952-959.

\begin{abstract}
Diabetes has evidence in ancient literatures, though recently is being considered as one amongst the most emerging disease condition in both human and companion animals. Diabetes mellitus is one of the common endocrinopathy of dog characterized by hyperglycemia, glycosuria and weight loss. Reports suggests high fraction of canine population suffer with diabetes world over. Studies in different veterinary hospitals of United States suggest increase in cases of canine diabetes and decrease in case fatality rate over time. Increase in cases of canine diabetes worldwide is attributed to awareness amongst pet owners, better veterinary health facilities, breed preferences by dog owners, increase dependence on commercial feeds, obesity, etc. Diabetes in most dogs is immune mediated and insulin dependent. Breed predisposition in canine is attributed to dog leukocyte antigen gene pool encoding form major histocompatibility complex-II molecules, however research is still underway. Diagnosis of diabetes still relies on blood sugar evaluation for screening of canine population, though many other diagnostic methods have shown promising benefits including measurement of fructosamine and glycated haemoglobin. Management of diabetes in dog is based on insulin therapy, diet modification and exercise. Use of oral anti-diabetics drugs in canine is limited though experimental studies have shown promising results. Alternative therapies have been explored, but only a few approaches have shown promise for clinical application.
\end{abstract}

Keywords: canine, diabetes mellitus, emergence, fructosamine, glycated haemoglobin, insulin, streptozotocin.

\section{Introduction}

Diabetes mellitus (DM) is one of the common metabolic disorders affecting middle-aged to geriatric dogs characterized by hyperglycemia, glycosuria and weight loss, resulting from absolute or relative deficiency of insulin. Research on DM has caught attention of researchers globally. Most of these findings were experiments undertaken in dog and very few literatures are available as case reports and retrospective studies with respect to spontaneous DM in canine population. Above all, studies on diabetes in canine population of Asian countries are still under preliminary stages or not considered at all. However, spontaneous cases of canine DM has increased globally due to factors such as obesity, alteration in feeding habits, owner inattention, lack of awareness and advancement in diagnosis. In the recent few years, DM in human population shows an emerging statistics and Asian population are at increased risk [1]. Research conducted on canine DM has direct implication on studying this disease in humans [2]. Thus, there is a need to review current status of DM in canine population with respect to past efforts, present advancement, clinical presentations, diagnostic and manage mental practices.

Copyright: The authors. This article is an open access article licensed under the terms of the Creative Commons Attributin License (http:// creative commons.org/licenses/by/2.0) which permits unrestricted use, distribution and reproduction in any medium, provided the work is properly cited.

\section{Timeline Review}

Diabetes was described as one of the first disease in Egyptian manuscript of antiquity characterized by condition similar to DM Type 1 as "too great emptying of the urine” in early second century [3]. In and around fifth century Indian physicians also identified the disease and named it as madhumeha or "honey urine" signifying glycosuria as one of the important clinical presentation of DM. Aretaeusthe Cappadocian (30-90 A.D) named the disease diabetes from a Greek word diabainein which means "siphon" or "a passer through" to describe the polyuria and polydipsia (PU-PD) [4]. Avicenna (980-1027 A.D) was first to describe complications of diabetes including gangrene. The term "mellitus" meaning honey is a Latin word first used by Willis (1621-1675) as nomenclature for diabetes [5]. The hormone discovered by Banting and Best in 1921, was named insulin after successful treatment of diabetic patients using this hormone by Macleod after purification by Collip [6]. Diabetes in dogs was recognized at least 40 years prior to insulin discovery [7]. Von Mering and Minkowski in 1889 first described the canine clinical signs of PU-PD to be associated with the presence of glucose in the pancreatectomized urine of dogs [8]. Alloxan synthesized in 1818 was considered as representative drug for inducing diabetes by necrosis of the endocrine beta cells in 1940s followed by streptozocin in animal models [9]. The association between major histocompatibility 
complex (MHC) genes and diabetes in human was first reported in 1970s by Nerup et al. [10]. Recently, an advanced single session of gene therapy has been demonstrated as a long-term cure for diabetes in a large animal model by the researchers from the Universitat Autonoma De Barcelona, led by Fatima Bosch in 2013.

\section{Experimental Models for DM}

Experimental studies for undertaking research on DM has relied on developing several animal models by inducing damage to the pancreas through either surgical or chemical and genetic manipulation. Animal models of DM are classified as spontaneous or secondary. The earliest animal model of DM was a pancreatomized dog in the 1880s, and many others pancreatomized laboratory animal models like rabbit have been used for diabetic studies [11]. Most experiments on diabetes have been carried out in rodents, although studies have also been reported on the dog and other large animals. Use of animal models in diabetes research has been reviewed elaborately including genetically modified animal models by several workers [12-16].

Streptozotocin (STZ) and alloxan (percentage ratio of 69:31) are by far the most frequently used drugs and this chemical model has been useful for the study of multiple aspects of the disease [14]. Both these drugs exert their diabetogenic action when administered either intravenously (i.v.), intra-peritoneally (i.p.) or subcutaneously (s.c.). Alloxan and STZ are toxic glucose analogues that preferentially accumulate in pancreatic beta $(\beta)$ cells via the glucose transporter 2 [17]. The dose of these agents required for inducing diabetes depends on the animal species, route of administration and nutritional status. Alloxan (oxygenated pyrimidine derivative) was isolated by Brugnatelli in 1818 and named by Wöhler and Liebig in 1838 [9]. It was considered a representative drug for diabetes capable of inducing necrosis of the pancreatic $\beta$ cells in 1940s. The most frequently used i.v. dose of alloxan in rats is $65 \mathrm{mg} / \mathrm{kg}$, but its effective dose must be higher when administered by i.p. or s.c. route [18]. I.p. administration of $150 \mathrm{mg} / \mathrm{kg}$ of alloxan monohydrate induced hyperglycaemia in about $75 \%$ of the treated rats [18]. STZ (glucosamine-nitrosourea compound) is a naturally occurring chemical that is particularly toxic to the insulin-producing $\beta$ cells of the pancreas in mammals. STZ was first used as antibiotic and incidentally found to be toxic to pancreas, thus later used for inducing diabetes. STZ is the most commonly used chemical for experimental induction of diabetes in rodents. However, chronic experimentation with STZ has reported side effects like development of functioning insulinoma, high incidence tumours of kidney and liver [19] suggesting its oncogenic action. The effect of $160 \mathrm{mg} / \mathrm{kg}$ of i.v. STZ injection was equivalent to that of $200 \mathrm{mg} / \mathrm{kg}$ of i.p. STZ injection in modulating blood glucose level [9].

\section{Types of DM in Dog}

DM in dog can be classified as either Type 1 or Type 2. Most dogs suffer from Type 1 diabetes in which there is lack of insulin production and dependency on external insulin for survival. In Type 2 insulin, production is impaired along with an inadequate response to the hormone. Unlike human beings whether dogs have Type I or Type II, DM has rarely been determined, however most diabetic dogs (>50\%) are thought to have a disease similar to Type I DM of humans and are insulin dependent [20]. Catchpole et al. [21] have classified canine DM into insulin deficiency diabetes (IDD) with absolute insulin deficiency and insulin resistance diabetes (IRD) with relative insulin deficiency. IRD can complicate and progress to secondary IDD as an outcome of $\beta$ cell loss in pancreas associated with uncontrolled hyperglycaemia. IDD is characterized by insulin deficiency caused by auto-immune-mediated destruction of $\beta$ cells. In IDD dogs there is no increase in insulin or C-peptide by stimulation of $\beta$ cells of pancreas located in islets of Langerhans with glucose or glucagon, suggesting that $\beta$-cells are lost or has become unresponsive [22]. Immune mediated damage to $\beta$ cells by antibodies against $\beta$ cells has been suggested in the pathogenesis of DM in dog [23]. In nearly half of the newly diagnosed cases of DM in dogs, antibody against $\beta$ cells has been reported [24]. However, lymphocytic infiltration of islets is infrequently detected in dogs. IRD in the canine population is comparatively less and often results from insulin resistance and/or inadequate insulin production or secretion by $\beta$ cells [20].

The third form of DM though a type of IRD, has also been reported called as gestational DM (GDM), or diestrus-associated DM in dog [25]. The published reports suggest that GDM affects mainly middle-aged bitches in the latter half of gestation with a breed predisposition toward Nordic Spitz [25]. However, authors have a view that this predisposition may be related to either over-representation of the breed or vary depending on proportions of intact bitches in the base population or less number of samples studied. GDM has been reported to resolve within days to weeks after whelping or termination of pregnancy. GDM is attributed to reduced insulin sensitivity in healthy bitch after 1 month of gestation [26] and increase levels of progesterone [27]. Higher level of progesterone causes glucose intolerance and overt diabetes during diestrus in bitches, and it also stimulates the mammary gland of bitches to produce growth hormone, which is a potent inducer of insulin resistance [28]. Juvenile diabetes in canine, a form of IDD has also been reported and is particularly prevalent in golden retrievers, German shepherd and keeshonds [29]. Pre-diabetic form in the dog has been suggested in non-diabetic dogs with chronic pancreatitis due to $\beta$-cell loss [30]. 


\section{Epizootiology}

Available literature suggests that spontaneous canine DM has not been considered and investigated in canine population of Asian countries including India. There are limited studies on breed disposition, incidence, susceptibility, clinical characteristic and response to use of various interventions available for its management and control. Major works are focused on experimental rodent studies and hovering mainly on evaluation of herbal plants and/or its extracts. However, the scenario is different with respect to research and findings on spontaneous as well as experimental induced DM in affluent countries. Recent trends indicate steep rise (32\%) in cases of canine DM from 2006 to 2010 according to Banfield Hospital of USA [31]. One such study suggests that diabetes currently develops in about 1 in 500 dogs and 1 in 250 housecats [32,33]. Similarly, Guptill et al. [34] reported that prevalence of canine DM presented to veterinary teaching hospitals of Purdue University, USA increased from $0.19 \%$ in 1970 to $0.64 \%$ in 1999 . During the same time period the case-fatality rate decreased from $37 \%$ to $5 \%$ signifying increase in incidence and understanding of diabetes management in canine. Estimated prevalence of canine DM in United Kingdom is 0.32\% [32]. A recent study carried out by researchers of Indian Veterinary Research Institute; Izatnagar indicate that canine DM strikes Indian dog population at quite high frequency [35]. Out of the total of 251 dogs of different breeds screened for diabetes, 27 (10.88\%) were found to be diabetic based on random blood sugar and relevant clinical parameters [35]. However, no clear understanding was reported with respect to risk groups and other factors related with spontaneous canine DM. Understanding on breed, age and sex as risk factors has been reported by many researchers globally. Breeds like Poodles, Keeshounds, Alaskan Malamutes, Finnish Spitzes, Miniature Schnauzers, Samoyed, Cairn Terrier, Bichon Frise and English Springer Spaniels are considered under high risk for spontaneous DM while German Shepherd, Cocker Spaniels, Collies and Boxers breeds are included in low risk group [21,34]. Breed susceptibility for DM and influences of genetic factors, specific genes and inheritance patterns are importunate areas under investigation by researchers globally. DM in most susceptible breeds of dogs has been associated with dog leukocyte antigen (DLA) gene encoding for major MHC Class II molecules located on canine chromosome 12, with similar haplotypes and genotypes [36]. MHC Class II are responsible for presenting antigen to T lymphocyte. Some DLA genes are monomorphic, and others loci are polymorphic in the canine population. Therefore depending on the variation in the gene pool of DLA, the susceptibility to autoimmune diseases varies and so the breed predisposition to canine DM [21]. Polymorphisms in the canine cytotoxic T-lymphocyte antigen four promoters and other immune response genes are associated with susceptibility to DM in many pedigree breeds. Gender susceptibility for canine DM seems inappropriate at young age of the canine population attributed to low incidence of disease. However, the male-female risk ratio has a predominance of females at older ages [29]. Similar predisposition was also reported in a study carried out in Bareilly by Indian Veterinary Research Institute, Izatnagar with $70.37 \%$ cases reported in female [35]. Aging has been considered as one of the important factor in canine DM. Canine DM mostly reported in middle age to old age dogs between 5 and 12 years of age [37]. Metabolic disorder of lipids in old age dogs may lead to obesity and diabetes due to hyperlipidemia [38].

The etiology of DM in dogs seems multi-factorial (Figure-1). Factors including obesity, diet, exposure to toxic chemicals/drugs that cause insulin resistance, immune-mediated destruction of islet cells [23], destruction of islet cells secondary to pancreatitis and other endocrinopathies are few amongst many influencing pathogenesis of canine DM. Extensive pancreatic damage, which likely results from chronic pancreatitis, is responsible for the development of diabetes in approximately $28 \%$ of diabetic dogs [39]. Hypertriglyceridemia has been proposed as a possible inciting cause of canine pancreatitis [40] and is commonly seen in diabetic dogs. All these factors can be further influenced by breed susceptibility explained above. The most common combinations of endocrine disorders of dogs are DM and hyperadrenocorticism, followed by hypoadrenocorticism and hypothyroidism [41]. Diagnosis of canine DM has been found to be correlated with season with the incidence peaking in winter [42]. Environmental factors such as feeding high-fat diets, lipemia and disturbances in lipid metabolism have been implicated as potential etiological factors in dogs with obesity-associated pancreatitis [43], and have a role to play in disease progression.

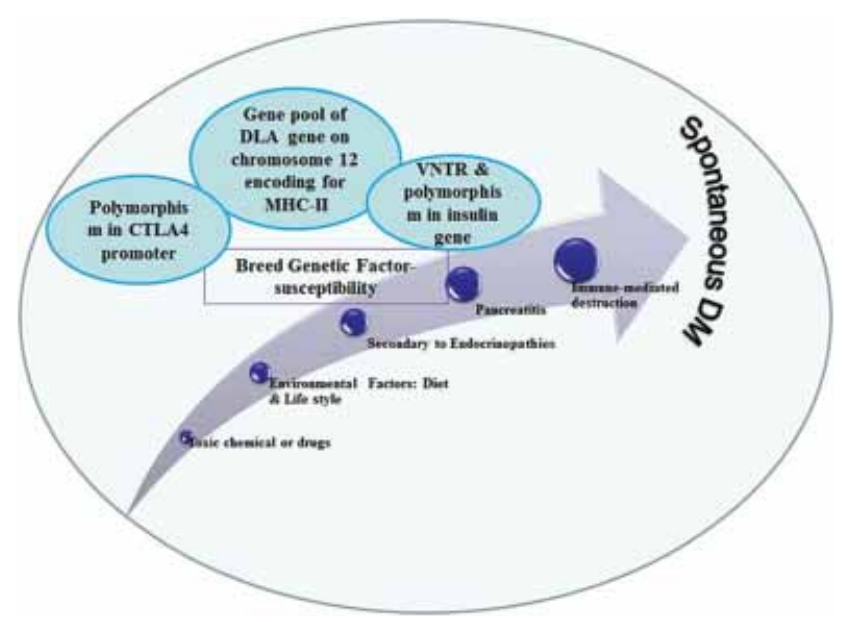

Figure-1: Schematic diagram showing possible factors responsible for spontaneous diabetes mellitus, CLLA4: Cytotoxic T-lymphocyte antigen 4, DLA: Dog leucocyte antigen, VNTR: Variable number of tandem repeats. 
Various other possible inflicting factors contributing to increase incidence of DM are urbanisation of human population and engagement in occupations ensuing change in lifestyle of pet dogs, more dependence on commercial pet food, lack of exercise, preference for breeds predisposed to DM [44].

\section{Clinical Presentation of DM}

The clinical presentation in most cases of canine DM are PU-PD, persistent hyperglycaemia, glycosuria and ketonuria [45]. On a perusal of available literature on spontaneous cases of DM in dog, very few references are available from Asia including India. Most case reports and studies available are restricted to USA, Australia and UK. Earliest and elaborative description of DM in dogs and cats was published by Hjärre [46]. Canine DM is an assorted disorder with several pathological mechanisms and complication of abnormal metabolism. Abnormal carbohydrate metabolism is responsible for the PU-PD and cataract formation in diabetic dogs. Altered fat metabolism is primarily responsible for hyperlipidemia, ketone production and hepatic changes. Cataracts develop within 5-6 months of diabetic dogs, and approximately $80 \%$ will have significant cataract formation by 16 months [47]. The onset of diabetic cataract involves several factors such as osmotic changes in the lens, glycosylation of structural proteins, and a decreased concentration of antioxidants [48]. Spontaneous lens capsule rupture associated with DM, cataract and rapid lens intumescence occurs in the dog [49]. Unlike human diabetes retinopathy, aqueous humor concentration of vascular endothelial growth factor in diabetic dogs are not higher than health dog and may have a protective function against development of diabetic retinopathy [50]. Observed clinical findings of untreated, undiagnosed diabetic dogs are lethargy, weight loss, increased hunger, poor coat and reduced immunity [51] possibly attributed to decreased tissue utilization of nutrients. Ketoacidosis and hyperglycemic hyperosmolar non-ketotic syndrome are two serious and potentially life-threatening complications of $\mathrm{DM}$. These forms of diabetes are often precipitated by concurrent diseases such as pyelonephritis, pancreatitis, pyometra, hyperadrenocorticism, renal and heart failure. Ketosis in diabetic dogs has been attributed to the glucagon-insulin ratio and most diabetic dogs with a serum ketone concentration $>1000 \mu \mathrm{mol} / \mathrm{L}$ have a propensity to have lower serum insulin $(<5 \mu \mathrm{U} / \mathrm{mL})$ concentration [45]. Pregnancy in bitches results in suppressed intracellular transport of glucose causing hyperglycemia. Pregnant bitches also have suppressed ability to produce glucose in response to hypoglycemic state and a slight deprivation of food may cause hypoglycemia and ketonemia [52].

\section{Advances in Diagnosis of DM}

Diabetic dogs are often undiagnosed in Asian countries including India attributed to lack of awareness amongst both pet owners and veterinary clinicians. This assumption is reflected based on the very few reports of canine DM from the region, though the actual number of cases in the canine population is underreported. Conventionally, diagnosis of canine DM is based on persistent hyperglycemia, and glucosuria accompanied with appropriate clinical signs. Blood glucose concentration for evaluation of DM is limited by the fact that it fluctuates with the time of the day, stress and often do not reflect the overall glycemic control of a dog. Normal reference values for blood glucose in health dog range from 75 to $120 \mathrm{mg} / \mathrm{dl}$ [53]. The renal threshold for glucose is $\sim 180 \mathrm{mg} / \mathrm{dl}$ [53]. Glycosuria is clinically present when blood sugar level exceeds this limit. In dogs diagnosis of immune-mediated DM can be evaluated by $\beta$-cell specific antibodies and C-peptide concentration. Measurement of C-peptide provides a sensitive, well accepted, and clinically validated assessment of $\beta$-cell function in human patients [54].

Measurements of serum fructosamine and glycated hemoglobin (GHb) are increasingly used to complement blood glucose concentration to diagnose canine DM and to monitor the response to treatment [55]. However, fructosamine has advantage over $\mathrm{GHb}$ based on simplicity and cost benefits of estimation methods. Fructosamine can reflect glycemic control over the past 2-3 weeks while GHb can reflect the same for past 6-8 weeks. GHb is non-enzymatic and irreversible glycosylation of hemoglobin A1c. Haberer and Reusch [56] reported reference range of GHb for healthy and diabetic dog varying between 2.3-4.3\% and $4.5-8.6 \%$, respectively. The reported upper limit of serum fructosamine in dog is $374 \mu \mathrm{mol} / \mathrm{L}$ [57]. Serum fructosamine can also guide in differentiating primary renal glycosuria and Fanconi syndrome in dogs. In insulin treated diabetic dogs, concentrations of fasting blood sugar vary between 100 and $300 \mathrm{mg} / \mathrm{dl}$, blood $\mathrm{GHb} \leq 7.5 \%$, and serum fructosamine $\leq 525 \mu \mathrm{mol} / \mathrm{L}$ [58]. Serum glycated albumin (GA) has been suggested as an alternative to fructosamine and reported to be useful diagnostic indicator to monitor glycemic control in diabetic dogs [59]. In diabetic dog, serum GA concentrations reported as $>11.9 \%$. In diabetic dogs, high concentrations of aldose reductase are found in tissues of the crystalline lens, neurons and erythrocytes. The sorbitol concentration in erythrocytes was found significantly higher in diabetic dogs with ketonuria [48]. Serum canine pancreatic lipase immunoreactivity (cPLI) is considered as a sensitive marker for pancreatic inflammation in dogs [60]. Elevated serum cPLI concentration within the range diagnostic for pancreatitis has been reported in a small fraction of diabetic dogs [61,62].

\section{Management Strategies for Canine DM}

Most spontaneous cases of canine diabetes are insulin dependent. Uses of insulin and diet modification are the two mainstays in management of diabetes 
in canine. Most diabetic dogs suffer from insulin deficiency and require exogenous insulin. Insulin are injected s.c. Once daily, although administration twice daily can lead to better glycemic control and reduced risk of insulin-induced hypoglycemia. Commonly used insulin products in canine DM are isophane, lente and ultra-lente insulin. However, only two insulin products for use in diabetic dogs are presently approved by Food and Drug Administration (FDA). One of these is a porcine lente product [63], the other is vetsulin (porcine insulin zinc suspension) approved by FDA in 2014. Vetsulin is the most preferred product used for management of canine DM, and its duration of action is about $12 \mathrm{~h}$ [64]. Protamine zinc insulin (PZI) is longer acting insulin but is currently approved for use in cats only. Use of recombinant human PZI has been demonstrated to significantly decrease mean 10-h serum blood glucose and serum fructosamine concentration after 60 days of treatment [65]. The use of lantus insulin reported practical success both in dogs and cats [66]. Since lantus is long acting insulin, it has the advantage that it can be used once a day. Most dogs are well controlled on insulin at $0.5 \mathrm{U} / \mathrm{kg}$ repeated every $12 \mathrm{~h}$ with a range of 0.2 to $1.0 \mathrm{U} / \mathrm{kg}$ body weight [67]. Rucinsky et al. [64] recommend a starting dose of $0.25 \mathrm{U} / \mathrm{kg}$ every $12 \mathrm{~h}$ along with feeding equally sized meals twice daily at the time of insulin injection.

Most anti-diabetic drugs that are commercially available may not be useful in dog. Anti-diabetic drugs act either by stimulating insulin release by the $\beta$ cells of the pancreas or by increasing the sensitivity of target organs to insulin or decreasing the rate of glucose absorption from the intestine. Commercials drugs used or available for the purpose are enlisted in Table-1. Baring a few anti-diabetic drugs, data with respect to dosing in dogs are not available. Treatment with the alpha glucosidase inhibitor (acarbose) improves glycaemic control in diabetic dogs [68]. In dogs, first-generation sulphonylureas exert a positive inotropic effect [69]. In fasted dogs, repaglinide have shown strong and long lasting hypoglycaemic effect [70]. The potency of repaglinide was reported to be higher and faster in action compared with glimepiride and glibenclamide in the animal model [71].
Alternative therapies for canine DM have been studied, but only a few have reached its clinical application. In surgical therapies, the first successful islet transplant was credited to Rundles and Swan [72]. Use of encapsulate islet in diabetes management, current status and its future needs has been exhaustively reviewed [73]. Prochorov et al. [74] reported successful intravascular xenotransplantation of macro-encapsulated pancreatic islet cells in Type 1 DM human patients. Micro-capsules using alginate or similar hydrogels encapsulate individual islets in rodents was found useful $[75,76]$. Reduction of encapsulated islet mass for clinical transplantation is in progress. Use of implant for clinical cases and its efficacy is still under process of understanding and development. Viral vector based gene therapy using adeno-associated virus encoding for glucokinase and insulin in canine diabetes had desirable effects consistently for consecutive 4 years of study [77]. The same study has also been successfully undertaken in mouse's model [78]. Nevertheless, further works are in the pipeline for the long-term cure of DM in dogs and humans which would harbinger innovative techniques to get rid of this royal disease.

\section{Conclusions}

Canine diabetes has emerged as an important endocrinopathy in middle to old age dogs globally. Diabetes was first described in Egyptian manuscript of antiquity in early second century; however research and understanding of the disease is progressing. Canine DM can be broadly classified into IDD and IRD along with some other forms, the nomenclature of which can reasonably fit this classification. For inducing diabetes in the animal model, although many chemicals are available, the two most commonly used are streptozocin and alloxan. Insights on human diabetes are often based on experimental studies carried out in the canine model. Clinical studies have shown that natural incidence of canine DM varies geographically. The predisposing factors precipitating the canine DM can be due to breeding preference, base population, lifestyle and occupational changes. Advancement in the research to understand the genetic basis of this disease is also under progression using various animal models.

Table-1: Oral drugs available for use in DM.

\begin{tabular}{|c|c|c|c|c|}
\hline Class & Drug & Dose & Mechanism & References \\
\hline Biguanides & Metformin & $500-1700 \mathrm{mg} / \mathrm{dog}$ & $\begin{array}{l}\text { Decreases amount of glucose release } \\
\text { from liver }\end{array}$ & $\begin{array}{l}\text { Balogh et al., 2008; } \\
\text { Mosallanejad et al., } 2013\end{array}$ \\
\hline Sulfonylureas & $\begin{array}{l}\text { Glimepiride } \\
\text { Glipizide }\end{array}$ & $\begin{array}{l}2 \mathrm{mg} \mathrm{SID} \\
1 \mathrm{mg} / \mathrm{kg}\end{array}$ & $\begin{array}{l}\text { Stimulates the pancreas to release } \\
\text { more insulin }\end{array}$ & Putnam et al., 1981 \\
\hline $\begin{array}{l}\text { Alpha-glucosidase } \\
\text { inhibitors }\end{array}$ & Acarbose & $\begin{array}{l}12.5-50 \mathrm{mg} / \mathrm{dog} \\
\mathrm{BID}\end{array}$ & Slows the absorption of carbohydrate & Robertson et al. 1999 \\
\hline DPP-4 inhibitors & $\begin{array}{l}\text { Sitagliptin } \\
\text { Saxagliptin } \\
\text { Linagliptin }\end{array}$ & $2-4 \mathrm{mg} / \mathrm{day}$ & Slows the absorption of carbohydrate & - \\
\hline Meglitinides & Repaglinide & 0.5-1 mg/day & More sensitive to the effects of insulin & - \\
\hline
\end{tabular}

DM=Diabetes mellitus, DPP-4=Dipeptidyl-peptidase 4 
Canine DM is an assorted disorder with several pathological mechanisms leading to hyperglycemia and complication of abnormal metabolism. Serum fructosamine and GHb are now increasingly used to complement blood glucose concentration for diagnosis of canine DM. Most diabetic dogs suffer from insulin deficiency and require exogenous insulin. Insulin used depends on the availability and licensing of insulin for use in dog. However, research in this direction are still in infancy. Long acting insulin can facilitate dog owners in the management of DM. Experimental studies have shown potential for oral anti-diabetic drugs, however most have failed to find a place for clinical use in canine DM. Our progressive efforts in the direction of alternative therapies such as gene implants, micro-devices, stem cells and viral based vectors have not yet reached significance for clinical use in canine DM.

\section{Authors' Contributions}

All the authors have made a significant contribution in the collection of materials and compilation of the review article under the leadership of the first author.

\section{Competing I nterests}

The authors declare that they have no competing interests.

\section{References}

1. Abdullah, N., Attia, J., Oldmeadow, C., Scott, R.J. and Holliday, E.J. (2014) The architecture of risk for type 2 diabetes: Understanding Asia in the context of global findings. Int. J. Endocrin., 2014: 21.

2. Jeong, Y.W., Lee, G.S., Kim, J.J., Park, S.W., Ko, K.H., Kang, M., Kim, Y.K., Jung, E.M., Hyun, S.H., Shin, T., Jeung, E.B. and Hwang, W.S. (2012) Establishment of a canine model of human type 2 diabetes mellitus by overexpressing phosphoenolypyruvate carboxykinase. Int. J. Mol. Med., 30(2): 321-329.

3. Ripoll, B.C. and Leutholtz, I. (2011) Exercise and Disease Management. $2^{\text {nd }}$ ed. CRC Press, Boca Raton. p25.

4. Zajac, J., Shrestha, A., Patel, P. and Poretsky, L. (2010) The main events in the history of diabetes mellitus. In: Principles of Diabetes Mellitus, Springer, US. p3-16.

5. Major, R.M. (1932) Classic Description of Disease. $2^{\text {nd }}$ ed. Charles C Thomas, Springfield.

6. Das, A.K. and Shah, S. (2011) History of diabetes: From ants to analogs. J. Assoc. Physician India, 59: 6-7.

7. Gardiner, A. (2006) The history of canine diabetes part 1: Diabetes in animals before insulin. Vet. Times, 36: 10-11.

8. De Leiva-Hidalgo, A., Bruguès-Bruguès, E., and de Leiva-Pérez, A. (2011) From pancreatic extracts to artificial pancreas: History, science and controversies about the discovery of the pancreatic antidiabetic hormone. VII: Early clinical use of pancreatic extracts (1921-1923). Adv. Diabetol., 27: 15-26.

9. Sakata, N., Yoshimatsu, G., Tsuchiya, H., Egawa, S. and Unno, M. (2012) Animal models of diabetes for islet transplantation. J. Exp. Diabetes. Res., 2012: 11.

10. Nerup, J., Platz, P., Andersen, O.O., Christy, M., Lyngsoe, J., Poulsen, J.E., Ryder, L.P., Nielsen, L.S., Thomsen, M. and Svejgaard, A. (1974) HLA antigens and diabetes mellitus. Lancet, 2: 864-866.

11. Rees, D.A. and Alcolado, J. C. (2005) Animal models of diabetes mellitus. Diabetes Med., 22: 359-370.
12. Islam, M.S. and Loots du T. (2009) Experimental rodent models of type 2 diabetes: A review. Methods Find Exp Clin., 31(4): 249-261.

13. Chatzigeorgiou, A., Halapas, A., Kalafatakis, K., and Kamper, E. (2009) The use of animal models in the study of diabetes mellitus. In Vivo, 23(2): 245-258.

14. Etuk, E.U. (2010) Animals models for studying diabetes mellitus. Agric. Biol. J. North Am., 1: 130-134.

15. King, A.J. (2012) The use of animal models in diabetes research. Br. J. Pharmacol., 166: 877-894.

16. Eddouks, M., Chattopadhyay, D. and Zeggwagh, N.A. (2012) Animal models as tools to investigate antidiabetic and anti-inflammatory plants. J. Evid. Based Complement. Alternat, Med., 2012: 142087.

17. Lenzen, S. (2008) The mechanisms of alloxan- and streptozotocin-induced diabetes. Diabetologia, 51(2): 216-226.

18. Etuk, E.U. and Muhammed, B.J. (2010) Evidence based analysis of chemical method of induction of diabetes mellitus in experimental rats. Int. J. Pharm. Sci., 1: 139-142.

19. Yamagami, T., Miwa, A., Takasawa, S. and Yamamoto, H. (1985) Introduction of rats pancreatic - $\beta$-cell tumour by the combined administration of streptozotocin or alloxan and poly (adenosine diphosphate ribose) synthetase inhibitors. Cancer Res., 45(4): 1845-1849.

20. Feldman, E.C. and Nelson, R.W. (1996) Canine and Feline Endocrinology and Reproduction. $2^{\text {nd }}$ ed. W. B. Saunders, Philadelphia, PA.

21. Catchpole, B., Kennedy, L.J., Davisony, L.J. and Ollier, W.E.R. (2008) Canine diabetes mellitus: From phenotype to genotype. J. Small Anim. Pract., 49(1): 4-10.

22. Montgomery, T.M., Nelson, R.W., Feldman, E.C., Robertson, K. and Polonsky, K.S. (1996) Basal and glucagon-stimulated plasma $\mathrm{C}$ peptide concentrations in healthy dogs, dogs with diabetes mellitus and dogs with hyperadrenocorticism. J. Vet. Intern. Med., 10(3): 116-122.

23. Davison, L.J., Walding, B., Herrtage, M.E. and Catchpole, B. (2008) Anti-Insulin antibodies in diabetic dogs before and after treatment with different insulin preparations. J. Vet. Intern. Med., 22(6): 1317-1325.

24. Rand, J.S., Fleeman, L.M., Farrow, H.A., Appleton, D.J. and Lederer, R. (2004) Canine and feline diabetes mellitus: nature or nurture? J. Nutr., 1348 Suppl: 2072S-2080S.

25. Fall, T., Kreuger, S.J., Juberget, A., Bergström, A. and Hedhammar, A. (2008) Gestational diabetes mellitus in 13 dogs. J. Vet. Intern. Med., 22(6): 1296-1300.

26. Concannon, P.W. (1986) Canine pregnancy and parturition. Vet. Clin. North Am. Small, 16(3): 453-475.

27. Kim, Ah.Y., Kang, J.H. and Yang, M.P. (2012) Transient diestrus-related diabetes mellitus in a dog. J. Biomed. Res., 13: 265-267.

28. Mared, M., Catchpole, B., Kampe, O. and Fall, T. (2012) Evaluation of circulating concentrations of glucose homeostasis biomarkers, progesterone, and growth hormone in healthy Elkhounds during anestrus and diestrus. Am. J. Vet. Res., 73: 242-247.

29. Neiger, R., Jaunin, V.B. and Boujon, C.E. (1996) Exocrine pancreatic insufficiency combined with insulin-dependent diabetes mellitus in a juvenile German shepherd dog. J. Small Anim. Pract., 37: 344-349.

30. Caney, S. (2013) Pancreatitis and diabetes in cats. Vet. Clin. North Am. Small., 43(2): 303-317.

31. Anonymous. (2011) Diabetes mellitus. In: Banfield Pet Hospital ${ }^{\circledR}$ State of Pet Health 2011 Report. Vol. 1. p12.

32. Catchpole, B., Ristic, J.M., Fleeman, L.M. and Davison, L.J. (2005) Canine diabetes mellitus: can old dogs teach us new tricks? Diabetologia, 48(10): 1948-1956.

33. McCann, T.M., Simpson, K.E., Shaw, D.J., Butt, J.A. and Gunn-Moore, D.A. (2007) feline diabetes mellitus in the UK: The prevalence within an insured cat population and a questionnaire-based putative risk factor analysis. J. Feline. Med. Surg., 9(4): 289-299.

34. Guptill, L., Glickman, L. and Glickman, N. (2003) Time 
trends and risk factors for diabetes mellitus in dogs: Analysis of veterinary medical data base records (1970-1999). Vet. J., 165(3): 240-247.

35. Anonymous. (2012) Management of chronic pancreatic disorders with special reference to diabetes mellitus in dogs. In: Annual Report of Indian Veterinary Research Institute, Izatnagar. p56.

36. Catchpole, B., Adams, J.P., Holdera, A. L., Shortc, A.D., Ollierc, W.E.R. and Kennedyc, L.J. (2013) Genetics of canine diabetes mellitus: Are the diabetes susceptibility genes identified in humans involved in breed susceptibility to diabetes mellitus in dogs? Vet. J., 195(2): 139-147.

37. Hess, R.S. (2010) Insulin resistance in dogs. Vet. Clin. North Am. Small, 40(2): 309-316.

38. Kawasumi, K., Kashiwado, N., Okada, Y., Sawamura, M., Sasaki, Y., Iwazaki, E., Mori, N., Yamamoto, I. and Arai, T. (2014) Age effects on plasma cholesterol and triglyceride profiles and metabolite concentrations in dogs. BMC Vet. Res., 10: 57.

39. Alejandro, R., Feldman, E.C., Shienvold, F.L. and Mintz, D.H. (1988) Advances in canine diabetes mellitus research: Etiopathology and results of islet transplantation. J. Am. Vet. Med. Assoc., 193(9): 1050-1055.

40. Verkest, K.R., Fleeman, L.M., Morton, J.M., Groen, S.J., Suchodolski, J.S., Steiner, J.M. and Rand, J.S. (2012) Association of postprandial serum triglyceride concentration and serum canine pancreatic lipase immunoreactivity in overweight and obese dogs. J. Vet. Intern. Med., 26: 46-53.

41. Blois, S.L., Dickie, E., Kruth, S.A. and Allen, D.G. (2011) Multiple endocrine diseases in dogs: 35 cases (1996-2009). J. Am. Vet. Med. Assoc., 238(12): 1616-1621.

42. Atkins, C.E. and MacDonald, M.J. (1987) Canine diabetes mellitus has a seasonal incidence: Implications relevant to human diabetes. Diabetes Res., 5(2): 83-87.

43. Lem, K.Y., Fosgate, G.T., Norby, B. and Steiner, J.M. (2008) Associations between dietary factors and pancreatitis in dogs. J. Am. Vet. Med. Assoc., 233(9): 1425-1431.

44. Klinkenberg, H., Sallander, M.H. and Hedhammar, A. (2006) Feeding, exercise, and weight identified as risk factors in canine diabetes mellitus. J. Nutr., 1367 Suppl: 1985S-1987S.

45. Durocher, L.L., Hinchcliff, K.W., DiBartola, S.P. and Johnson, S.E. (2008) Acid-base and hormonal abnormalities in dogs with naturally occurring diabetes mellitus. J. Am. Vet. Med. Assoc., 232(9): 1310-1320.

46. Hjärre, A. (1910) Sections befund beim diabetes mellitus beim rind. Berl. Munch. Tierarztl. Wochenschr., 26: 389-390.

47. Beam, S., Correa, M.T. and Davidson, M.G. (1999) A retrospective-cohort study on the development of cataracts in dogs with diabetes mellitus: 200 cases. Vet. Ophthalmol., 2(3): 169-172.

48. Comazzi, S., Bertazzolo, W., Bonfanti, U., Spagnolo, V. and Sartorelli, P. (2008) Advanced glycation end products and sorbitol in blood from differently compensated diabetic dogs. Res. Vet. Sci., 84(3): 341-346.

49. Basher, A.W. and Roberts, S.M. (1995) Ocular manifestations of diabetes mellitus: Diabetic cataracts in dogs. Vet. Clin. North. Am. Small., 25(3): 661-676.

50. Wilkie, D.A., Gemensky-Metzler, A.J., Colitz, C.M.H., Bras, I.D., Kuonen, V.J., Norris, K.N. and Basham, C.R. (2006) Canine cataracts, diabetes mellitus and spontaneous lens capsule rupture: a retrospective study of 18 dogs. Vet. Ophthalmol., 9: 328-334.

51. Fleeman, L.M. and Rand, J.S. (2008) Diabetes mellitus: Nutritional strategies. In: Pibot, P., Biourge, V. and Elliott, D.A., editors. Encyclopedia of Canine Clinical Nutrition. International Veterinary Information Service, Ithaca, NY. A4206.0308. Available from: http://www.ivis. org. [Updated on 31 Mar 2008].

52. Johnson, C.A. (2008) Glucose homeostasis during canine pregnancy: Insulin resistance, ketosis, and hypoglycemia. Theriogenology, 70: 1418-1423.
53. Bruyette, D. (2013) The Pancreas. The Merck Veterinary Manual. $8^{\text {th }}$ ed. Merck Sharp \& Dohme Corp., USA.

54. Palmer, J.P., Fleming, G.A., Greenbaum, C.J., Herold, K.C., Jansa, L.D., Kolb, H. and Steffes, M.W. (2004) C-Peptide is the appropriate outcome measure for type 1 diabetes clinical trials to preserve $\beta$-cell function report of an ADA workshop. Diabetes, 53(1): 250-264.

55. Jensen, A.L. (1995) Glycated blood proteins in canine diabetes mellitus. Vet. Rec., 137(16): 401-405.

56. Haberer, B. and Reusch, C.E. (1998) Glycated haemoglobin in various pathological conditions: investigations based on a new, fully automated method. J. Small Anim. Pract., 39(11): 510-517.

57. Reusch, C.E., Liehs, M.R., Hoyer, M. and Vochezer, R. (1993) Fructosamine. A new parameter for diagnosis and metabolic control in diabetic dogs and cats. J. Vet. Intern. Med., 7(3): 177-182.

58. Briggs, C.E., Nelson, R.W., Feldman, E.C., Elliott, D.A. and Neal, L.A. (2000) Reliability of history and physical examination findings for assessing control of glycemia in dogs with diabetes mellitus: 53 cases (1995-1998). J. Am. Vet. Med. Assoc., 217(1): 48-53.

59. Sako, T., Mori, A., Lee, P., Takahashi, T., Izawa, T., Karasawa, S., Furuuchi, M., Azakami, D., Mizukoshi, M., Mizutani, H., Kiyosawa, Y. and Arai, T. (2008) Diagnostic significance of serum glycated albumin in diabetic dogs. $J$. Vet. Diagn. Invest., 20(5): 634-638.

60. Steiner, J.M., Lees, G.E., Willard, M.D., Teague, S.R. and Williams, D.A. (2003) Serum canine pancreatic lipase immunoreactivity (CPLI) concentration is not altered by oral prednisone (abstract). J. Vet. Intern. Med., 17: 44.

61. Davison, L.J., Podd, S.L., Ristic, J.M., Herrtage, M.E., Parnham, A. and Catchpole, B. (2002) Evaluation of two pointof-care analysers for measurement of fructosamine or haemoglobin A1c in dogs. J. Small Anim. Pract., 43(12): 526-532.

62. Davison, L.J., Herrtage, M.E., Steiner, J.M., Williams, D.A. and Catchpole, B. (2003) Evidence of anti-insulin autoreactivity and pancreatic inflammation in newly-diagnosed diabetic dogs (abstract). J. Vet. Intern. Med., 17: 395.

63. Monroe, W.E., Laxton, D., Fallin, E.A., Richter, K.P., Santen, D.R., Panciera, D.L., Todd, L.T., Kimberly, A.W., John, R.H., Steve, H., Mark, R.F. and Shinn, J.S. (2005) Efficacy and safety of a purified porcine insulin zinc suspension for managing diabetes mellitus in dogs. J. Vet. Intern. Med., 19: 675-682.

64. Rucinsky, R., Cook, A., Haley, S., Nelson, R., Zoran, D.L. and Poundstone, M. (2010) AAHA diabetes management guidelines for dogs and cats. J. Am. Anim. Hosp. Assoc., 46(3): 215-224.

65. Maggiore, A.D., Nelson, R.W., Dennis, J., Johnson, E. and Kass, P.H. (2012) Efficacy of protamine zinc recombinant human insulin for controlling hyperglycemia in dogs with diabetes mellitus. J. Vet. Intern. Med., 26(1): 109-115.

66. Fernoaga, C., Codreanu, M. and Cornila, M. (2009) The use of lantus insulin in diabetes mellitus type I in dogs and cats. Sci. Vet. Med., XLII: 224-228.

67. Hess, R.S., Kass, P.H. and Ward, C.R. (2000) Breed distribution of dogs with diabetes mellitus admitted to a tertiary care facility. J. Am. Vet. Med. Assoc., 216(9): 1414-1417.

68. Nelson, R.W. (2000) Oral medications for treating diabetes mellitus in dogs and cats. J. Small Anim. Pract., 41(11): 486-490.

69. Ballagi-Pordány, G., Koltai, MZ., Aranyi. Z. and Pogátsa, G. (1991) Direct effect of hypoglycemic sulphonylureas on the cardiovascular system of dogs. Diabetes Res. Clin. Pract., 11(1): 47-52.

70. Mark, M. and Grell, W. (1997) Hypoglycaemic effects of the novel antidiabetic agent repaglinide in rats and dogs. $\mathrm{Br}$. J. Pharmacol., 121: 1597-1604.

71. Geisen, K. (1988) Special pharmacology of the new sulfonylurea glimepiride. Arzneim. Forsch. Drug Res., 38: $1120-1130$. 
72. Rundles, W.R. and Swan, H. (1957) Islet cell transplantation. Surg. Forum, 7: 502-506.

73. Scharp, D.W. and Marchetti, P. (2014) Encapsulated islets for diabetes therapy: History, current progress, and critical issues requiring solution. Adv. Drug. Deliv. Rev., 67-68: 35-73.

74. Prochorov, A.V., Tretjak, S.I., Goranov, V.A., Glinnik, A.A. and Goltsev, M.V. (2008) Treatment of insulin dependent diabetes mellitus with intravascular transplantation of pancreatic islet cells without immunosuppressive therapy. Adv. Med. Sci., 53: 240-244.

75. Sun, A.M., O’Shea, G.M. and Goosen. M.F.A. (1984) Injectable microencapsulated islet cells as a bioartificial pancreas. Appl. Biochem. Biotechnol., 10: 87-99.

76. Weber, C.J., Zabinski, S., Koschitzky, T., Wicker, L.,
Rajotte, R., D’Agati, V., Peterson, L., Norton, J. and Reemtsma, K. (1990) The role of CD4+ helper T cells in the destruction of microencapsulated islets xenografts in NOD mice. Transplantation, 49(2): 396-404.

77. Callejas, D., Mann, C.J., Ayuso, E., Lage, R., Grifoll, I., Roca, C., Andaluz, A., Ruiz-de Gopegui, R., Montané, J., Muñoz, S., Ferre, T., Haurigot, V., Zhou, S., Ruberte, J., Mingozzi, F., High, K.A., Garcia, F. and Bosch, F. (2013) Treatment of diabetes and long-term survival after insulin and glucokinase gene therapy. Diabetes, 62(5): 1718-1729.

78. Mas, A., Montane, J., Anguela, X.M., Munoz, S., Douar, A.M., Riu, E., Otaegui, P. and Bosch, F. (2006). Reversal of type 1 diabetes by engineering a glucose sensor in skeletal muscle. Diabetes, 55(6): 1546-1553. 